\title{
Successful switching from insulin to sulfonylurea in a 3-month-old infant with diabetes due to p.G53D mutation in KCNJ11
}

\author{
Jong Seo Yoon, $\mathrm{MD}^{1}$, \\ Kyu Jung Park, MD', \\ Young Bae Sohn, $\mathrm{MD}^{2}$, \\ Hae Sang Lee, MD, PhD', \\ Jin Soon Hwang, MD, PhD'
}

${ }^{1}$ Department of Pediatrics, Ajou University School of Medicine, Suwon, 2Department of Medical Genetics, Ajou University School of Medicine, Suwon, Korea
Received: 28 November, 2017 Revised: 28 December, 2017 Accepted: 5 April, 2018

Address for correspondence:

Hae Sang Lee, MD, PhD

Department of Pediatrics, Ajou University School of Medicine, 206 World cup-ro, Yeongtong-gu, Suwon 16499, Korea

Tel: +82-31-219-4427

Fax: +82-31-219-5169

E-mail: seaon98@ajoumc.or.kr

https://orcid.org/0000-0002-96844042
Permanent neonatal diabetes mellitus is most commonly caused by mutations in the ATP-sensitive potassium channel $\left(\mathrm{K}_{\text {ATP }}\right)$ subunits. Prompt initiation of sulfonylurea treatment can improve glycemic control in children with KCNJ11 mutation. In this report, we present a case of permanent neonatal diabetes caused by a mutation in the KCNJ11 gene that was successfully treated via early switching of insulin to sulfonylurea treatment. A 53-day-old female infant presented with diabetic ketoacidosis. Insulin was administered for the ketoacidosis and blood glucose regulation. At 3 months of age, using genomic DNA extracted from peripheral lymphocytes, direct sequencing of KCNJ11 identified a heterozygous mutation of c.158G>A (p.G53D) and confirmed the diagnosis of permanent neonatal diabetes mellitus. Subsequently, treatment with sulfonylurea was initiated, and the insulin dose was gradually tapered. At 4 months of age, insulin therapy was discontinued, and sulfonylurea (glimepiride, $0.75 \mathrm{mg} / \mathrm{kg}$ ) was administered alone. At 6 months after initiation of administration of sulfonylurea monotherapy, blood glucose control was stable, and no hypoglycemic events or developmental delays were reported. C-peptide levels increased during treatment with sulfonylurea. Early switching to sulfonylurea in infants with permanent diabetes mellitus owing to a KCNJ11 mutation could successfully help regulate glycemic control, which suggests the need for early genetic testing in patients presenting with diabetes before 6 months of age.

Keywords: Neonate, Diabetes mellitus, Mutation, KCNJ11 mutation, Sulfonylurea

\section{Introduction}

Neonatal diabetes mellitus (NDM) is characterized by the onset of diabetes before 6 months of age. NDM has an almost monogenic etiology and is considered to be a rare condition, with a prevalence of 1 in 100,000-300,000 live births. ${ }^{1)} \mathrm{NDM}$ includes permanent neonatal diabetes mellitus (PNDM), which requires insulin or oral sulfonylurea treatment for life, and transient NDM, which usually resolves at a median age of 12 weeks, but approximately $50 \%$ of cases relapse in adolescence or young adulthood. ${ }^{1)}$ PNDM is most commonly a result of heterozygous mutations of the genes KCNJ11 and ABCC8 encoding the ATPsensitive potassium channel $\left(\mathrm{K}_{\mathrm{ATP}}\right)^{1,2)}$ Approximately half of the cases are caused by a mutation in the KCNJ11 gene. ${ }^{1,3)}$ KCNJ11 mutations result in decreased sensitivity of the Kir6.2 subunits to ATP, with channel closure failure and consequently insufficient insulin release from the $\beta$-cells. ${ }^{2)}$ Developmental delay, epilepsy, and neonatal diabetes (DEND) syndrome are described in some patients with KCNJ11 mutations. ${ }^{1)}$ In most patients with $\mathrm{K}_{\mathrm{ATP}}$-related diabetes, oral sulfonylurea therapy promotes insulin secretion through the ATPindependent closure of overly active mutated channels. ${ }^{1-3)}$ Sulfonylureas represent a suitable 
therapy for patients with KCNJ11 mutations, instead of insulin therapy. However, not all patients are successfully treated with sulfonylurea. ${ }^{3)}$

Only a few cases of PNDM have been reported in Korea. ${ }^{47}$ Of the five cases, patients with p.K170R, p.V59M, and p.H186D mutations showed successful treatment with sulfonylurea., ${ }^{4,6)}$ Only patients with p.V59M mutation showed moderate developmental delay. ${ }^{6}$ Two cases of patients with p.R201H mutation have been reported. ${ }^{5,7)}$ One case was unsuccessfully treated with a sulfonylurea with no neurologic symptoms, ${ }^{7)}$ and another case showed DEND syndrome with a successful switch from insulin to sulfonylurea therapy. ${ }^{5)}$ Herein, we report a case of PNDM caused by a heterozygous p.G53D mutation in the KCNJ11 gene with successful glycemic control by initiating sulfonylurea treatment at 3 months of age.

\section{Case report}

A 53-day-old girl was hospitalized owing to diabetic ketoacidosis (DKA) and a generalized tonic-clonic seizure in March 2017. The patient was born at 38 weeks of gestation and demonstrated intrauterine growth retardation. She was delivered via normal spontaneous vaginal delivery and weighed $2,520 \mathrm{~g}$ (standard deviation score [SDS], -1.89) at birth. She was the first child and had no siblings. Her family had no history of diabetes. Laboratory results at diagnosis were as follows: blood glucose, $702 \mathrm{mg} / \mathrm{dL} ; \mathrm{pH}, 6.979$; $\mathrm{HCO}_{3}{ }^{-}, 4.5 \mathrm{mmHg}$; base excess, $-25.7 \mathrm{mmol} / \mathrm{L}$; total $\mathrm{CO}_{2}, 5 \mathrm{mmol} / \mathrm{L}$; sodium, $141 \mathrm{mEq} / \mathrm{L}$; corrected sodium, $149 \mathrm{mEq} / \mathrm{L}$; potassium, $6.5 \mathrm{mEq} / \mathrm{L}$; chloride, $105 \mathrm{mEq} / \mathrm{L}$; urine glucose, 3+; urine ketone, 3+; glycated hemoglobin $\left(\mathrm{HbA}_{\mathrm{c}}\right), 7.8 \%$; C-peptide, $<0.01 \mathrm{ng} / \mathrm{mL}$; insulin $6.6 \mu \mathrm{IU} / \mathrm{mL}$; insulin antibody $6.6 \%(0.0-7.0)$; glutamic acid decarboxylase II antibody, $0.59 \mathrm{U} / \mathrm{mL}(0.0-1.0)$; and islet cell antibody, negative. The patient recovered from DKA, and the continuous insulin treatment was subsequently discontinued. Instead, the patient had an injection of glargine (Lantus) once daily and regular insulin twice daily. Her insulin requirement gradually increased to $0.9 \mathrm{U} / \mathrm{kg} / \mathrm{day}$, and the seizure was no longer observed. No abnormal findings were observed on both the electroencephalogram and brain magnetic resonance image. She was hospitalized for a total of 14 days. Direct sequencing of the KCNJ11 and ABCC8 genes using genomic DNA extracted from peripheral lymphocytes was conducted during the hospitalization; her parents were not subjected to genetic testing. Six weeks later, direct sequencing of the KCNJ11 gene, encoding the Kir6.2 subunit of the KATP channel, confirmed the presence of a heterozygous mutation, KCNJ11:c.158G>A (p.G53D) (Fig. 1). $A B C C 8$ mutation was not detected. By then, the patient was 3 months of age, and insulin was administered at $1 \mathrm{U} / \mathrm{kg} /$ day. She could lift her head and did not demonstrate signs of developmental delay. We immediately started sulfonylurea (glimepiride) at $0.3 \mathrm{mg} / \mathrm{kg} /$ day and gradually tapered the insulin dosage. Five weeks later, insulin was discontinued, and the dosage of glimepiride was adjusted to $0.75 \mathrm{mg} / \mathrm{kg} / \mathrm{day}$. The patient is now 11 months of age, and her weight is $9.7 \mathrm{~kg}$
(SDS, 0.07). She can sit without help, pull herself to the standing position, and respond well to simple verbal requests. She is also able to pronounce simple words like "mama." She maintains excellent blood glucose control without hypoglycemic events, with an $\mathrm{HbA}_{1 \mathrm{c}}$ level of $6.3 \%$. Six months after the initiation of glimepiride therapy, her serum C-peptide level was $2.53 \mathrm{ng} /$ $\mathrm{mL}$, which was higher than the initial level of $<0.01 \mathrm{ng} / \mathrm{mL}$. Her current glimepiride dose is $0.6 \mathrm{mg} / \mathrm{kg} /$ day. Thus far, no further episodes of seizure have been reported.

\section{Discussion}

In this case, a 53-day-old girl was diagnosed with NDM due to a p.G53D mutation in KCNJ11 via early genetic testing upon hospital admission owing to DKA. Early switching from insulin to sulfonylurea treatment brought about successful blood glucose control.

NDM is a rare disease and is characterized by insulindependent persistent hyperglycemia that develops over the first 6 months of life. ${ }^{1)}$ Diabetes mellitus that begins before 6 months of age is unlikely to be caused by an autoimmune disease, but instead by monogenic inheritance. Mutations in the KCNJ11 and $A B C C 8$ genes account for $30 \%-50 \%$ of cases. ${ }^{1,3)}$ KCNJ11 gene mutations cause failure of $\beta$-cell KATP channel closure in response to intracellular ATP elevation, resulting in impaired insulin release. Sulfonylureas close the KATP channel in an ATP-independent manner ${ }^{1,3)}$ and have been reported to be a suitable treatment for patients with diabetes due to KCNJ11 mutations. $^{2,3,5,8-10)}$

Successful change from insulin therapy to sulfonylurea is known to be affected by the severity of clinical symptoms and duration of the disease. Pearson et al. ${ }^{3)}$ reported that $90 \%$ of patients (44 of 49) successfully switched from insulin to oral sulfonylureas and 5 patients (10\%) unsuccessfully switched. The success rate is lower in patients with DEND syndromes. Four of 5 patients $(80 \%)$ who were unable to switch to treatment with sulfonylureas had neurologic features. In contrast, 6

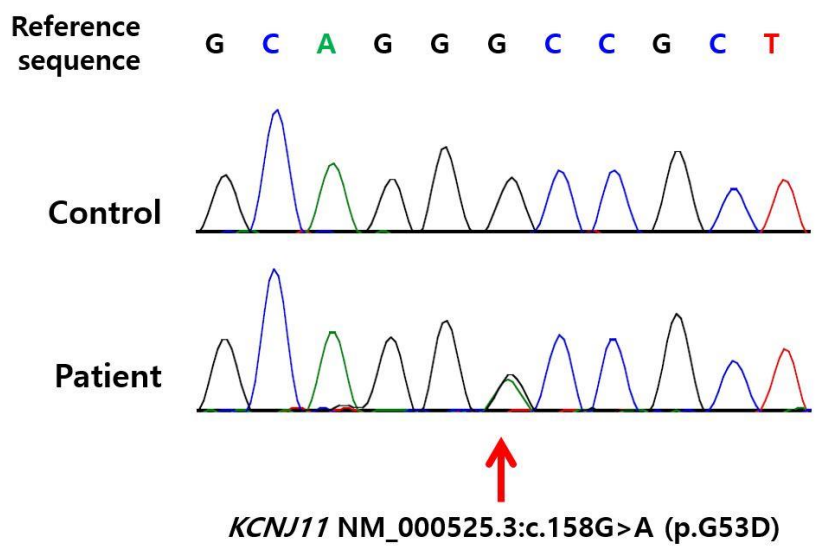

Fig. 1. Direct sequencing of the KCNJ11 gene revealed a heterozygous mutation of c.158G >A (p.G53D). 
patients (14\%) whose treatment was successfully switched to sulfonylureas had neurologic features. The median age of initiation of sulfonylurea treatment in the successful group was 6 years (interquartile range, 3-12 years); this was younger than the unsuccessful group with median age of 18 years (interquartile range, 6-35 years). Patients with p.R201H mutations have undergone both successful switching and unsuccessful switching from insulin to sulfonylurea. ${ }^{3,7)}$ p.R201H mutations in KCJN11 accompanying older age at initiation of sulfonylurea treatment are well-known factors influencing unsuccessful switching. In the case of unsuccessful switching from insulin to sulfonylurea, the patient with p.R201H mutations was 18 years old at the time of switching. ${ }^{7)}$ Other studies have reported that early initiation of sulfonylurea treatment has a beneficial effect on remission of neonatal diabetes. ${ }^{11)}$ In addition, in a murine model study, early sulfonylurea treatment leads to permanent remission of NDM. ${ }^{12)}$ This suggests that sulfonylurea treatment as early as possible may help in the successful switching insulin to sulfonylurea.

Treatment of DEND syndrome using sulfonylurea affects the prognosis. Previous clinical reports have shown that patients with DEND syndrome demonstrate improved neurological symptoms when a sulfonylurea is administered at an early stage of the diagnosis or adulthood. ${ }^{8,12,13)}$ There has been a report of a 17.9-year-old patient with DEND syndrome for whom sulfonylurea treatment was initiated and who achieved excellent glycemic control, but psychomotor retardation did not improve. ${ }^{5}$ As the brain develops continuously through infancy and beyond, the early administration of sulfonylureas may offer significant benefits to the neurodevelopmental outcomes. ${ }^{14)}$ Therefore, the importance of early administration of sulfonylureas is emphasized for a better neurodevelopmental outcome as well as for stable blood glucose control.

To our knowledge, there were no serious adverse effects reported in the treatment of sulfonylurea in NDM. Most cases reported on the efficacy of glimepiride as a treatment for KCNJ11 mutation, and there were some reports of the effects of gliclazide and glibenclamide. ${ }^{2,3,5,8-10)}$ All these drugs are second-generation drugs and are generally known to have an equivalent effect in lowering blood glucose concentration. ${ }^{15}$ Glibenclamide has been associated with an increased risk of hypoglycemia and cardiovascular-related mortality in adult type 2 diabetes mellitus patients. ${ }^{16)}$ Adverse effects due to glibenclamide administration in NDM patients have been reported with transient diarrhea ${ }^{17)}$ and tooth discoloration. ${ }^{18)}$ Significant side effects of administration of glibenclamide have not been reported in the treatment of NDM, and it is generally regarded as a safe treatment. According to a case report of glimepiride administration in NDM patients, a patient who was initially misdiagnosed with type 1 diabetes mellitus successfully converted to sulfonylurea treatment at 37 years of age and was given glimepiride due to the possible side effects of glibenclamide described above. ${ }^{9)}$

A total of 5 cases of NDM due to mutation of the KCNJ11 gene have been reported in Korea (Table 1). ${ }^{4-7)}$ The mean age at initiation of sulfonylurea treatment was $10.2 \pm 7.1$ years (3.8-18.0 years), and failure to switch from insulin therapy to sulfonylurea therapy was reported in one case. In our patient, p.G53D mutation was found, and the patient showed successful conversion from insulin to sulfonylurea treatment. Glimepiride was administered instead of glibenclamide. Our case showed that glimepiride is effective in achieving successful blood glucose control and causes no side effects for patients with NDM due to p.G53D mutation. The p.G53D mutation in KCNJ11 has previously been reported in a patient with DEND syndrome, ${ }^{8,19)}$ which comprises developmental delay, seizures during infancy, and improved motor features after switching from insulin to sulfonylurea treatment. ${ }^{8}$ Given the report of patients with this case and previously reported p.G53D mutation in patients with DEND syndrome, ${ }^{8)}$ patients with p.G53D mutation can also be considered to successfully convert from insulin to sulfonylurea treatment. The patient in the present case could not be diagnosed with DEND syndrome because developmental delay had not been confirmed yet. There is no developmental delay so far. However, considering that the p.G53D mutation is associated with DEND syndrome, ${ }^{8,19)}$ she

Table 1. Molecular and clinical features of permanent neonatal diabetes mellitus in Korea

\begin{tabular}{|c|c|c|c|c|c|c|}
\hline Variable & Kim et al., 2007 & Kim et al., 2007 & Heo et al., $2013^{7)}$ & Ahn et al., $2015^{4)}$ & Cho et al., $2017^{5)}$ & Present case, 2017 \\
\hline Sex & Female & Male & Male & Female & Male & Female \\
\hline Current age (y) & 6.5 & 3.8 & 19 & 7.5 & 18.7 & 0.4 \\
\hline Birth weight (g) & 2,300 & 3,000 & 2,400 & 2,500 & 2,750 & 2,580 \\
\hline Mutation & p.K170R & p.V59M & p.R201H & p.H186D & p.R201H & p.G53D \\
\hline Age at diagnosis (wk) & 6 & 6 & 3 & 8 & 7 & 9 \\
\hline Diabetic ketoacidosis & Yes & Yes & Yes & Yes & No & Yes \\
\hline Neurologic symptoms & Normal & $\begin{array}{l}\text { Moderate motor } \\
\text { and mental delay }\end{array}$ & Normal & Normal & DEND & Seizure \\
\hline Age at initiation (yr) & 6.5 & 3.8 & 18 & 4.8 & 17.9 & 0.3 \\
\hline Maintenance dose (mg/kg/day) & 0.9 & 0.9 & 2.2 & 0.3 & 2.4 & 0.8 \\
\hline Others & & & $\begin{array}{c}\text { Treatment } \\
\text { switching failure }\end{array}$ & & $\begin{array}{l}\text { Psychomotor } \\
\text { retardation was } \\
\text { not improved }\end{array}$ & \\
\hline
\end{tabular}

DEND, developmental delay, epilepsy, and neonatal diabetes. 
will require continuous monitoring of her developmental status.

In conclusion, genetic testing is an indispensable diagnostic tool for diabetes mellitus patients under 6 months of age because it can provide an accurate diagnosis and effective treatment, which improves the prognosis. Additionally, glimepiride administration in NDM associated with p.G53D mutation can effectively control blood glucose.

\section{Conflict of interest}

No potential conflict of interest relevant to this article was reported.

\section{References}

1. Naylor RN, Greeley SA, Bell GI, Philipson LH. Genetics and pathophysiology of neonatal diabetes mellitus. J Diabetes Investig 2011;2:158-69.

2. Gloyn AL, Pearson ER, Antcliff JF, Proks P, Bruining GJ, Slingerland AS, et al. Activating mutations in the gene encoding the ATP-sensitive potassium-channel subunit Kir6.2 and permanent neonatal diabetes. N Engl J Med 2004;350:1838-49.

3. Pearson ER, Flechtner I, Njølstad PR, Malecki MT, Flanagan SE, Larkin B, et al. Switching from insulin to oral sulfonylureas in patients with diabetes due to Kir6.2 mutations. N Engl J Med 2006;355:467-77.

4. Ahn SY, Kim GH, Yoo HW. Successful sulfonylurea treatment in a patient with permanent neonatal diabetes mellitus with a novel KCNJ11 mutation. Korean J Pediatr 2015;58:309-12.

5. Cho JH, Kang E, Lee BH, Kim GH, Choi JH, Yoo HW. DEND syndrome with heterozygous KCNJ11 mutation successfully treated with sulfonylurea. J Korean Med Sci 2017;32:1042-5.

6. Kim MS, Kim SY, Kim GH, Yoo HW, Lee DW, Lee DY. Sulfonylurea therapy in two Korean patients with insulintreated neonatal diabetes due to heterozygous mutations of the KCNJ11 gene encoding Kir6.2. J Korean Med Sci 2007;22:616-20.

7. Heo JW, Kim SW, Cho EH. Unsuccessful switch from insulin to sulfonylurea therapy in permanent neonatal diabetes mellitus due to an R201H mutation in the KCNJ11 gene: a case report. Diabetes Res Clin Pract 2013;100:e1-2.

8. Koster JC, Cadario F, Peruzzi C, Colombo C, Nichols CG, Barbetti F. The G53D mutation in Kir6.2 (KCNJ11) is associated with neonatal diabetes and motor dysfunction in adulthood that is improved with sulfonylurea therapy. J Clin Endocrinol Metab 2008;93:1054-61.

9. Arce KM, Pantalone KM. Not all diabetes in infants is type 1: a case report. Diabetes Ther 2016;7:369-75.

10. Ioacara S, Flanagan S, Fröhlich-Reiterer E, Goland R, Fica S. First case of neonatal diabetes with KCNJ11 Q52R mutation successfully switched from insulin to sulphonylurea treatment. J Diabetes Investig 2017;8:716-9.

11. Marshall BA, Green RP, Wambach J, White NH, Remedi MS, Nichols CG. Remission of severe neonatal diabetes with very early sulfonylurea treatment. Diabetes Care 2015;38:e38-9.

12. Remedi MS, Agapova SE, Vyas AK, Hruz PW, Nichols CG. Acute sulfonylurea therapy at disease onset can cause permanent remission of KATP-induced diabetes. Diabetes 2011;60:2515-22.

13. Slingerland AS, Hurkx W, Noordam K, Flanagan SE, Jukema JW, Meiners LC, et al. Sulphonylurea therapy improves cognition in a patient with the V59M KCNJ11 mutation. Diabet Med 2008;25:277-81.

14. Shah RP, Spruyt K, Kragie BC, Greeley SA, Msall ME. Visuomotor performance in KCNJ11-related neonatal diabetes is impaired in children with DEND-associated mutations and may be improved by early treatment with sulfonylureas. Diabetes Care 2012;35:2086-8.

15. Sola D, Rossi L, Schianca GP, Maffioli P, Bigliocca M, Mella $\mathrm{R}$, et al. Sulfonylureas and their use in clinical practice. Arch Med Sci 2015;11:840-8.

16. Pantalone KM, Kattan MW, Yu C, Wells BJ, Arrigain S, Jain $A$, et al. Increase in overall mortality risk in patients with type 2 diabetes receiving glipizide, glyburide or glimepiride monotherapy versus metformin: a retrospective analysis. Diabetes Obes Metab 2012;14:803-9.

17. Codner E, Flanagan S, Ellard S, García H, Hattersley AT. High-dose glibenclamide can replace insulin therapy despite transitory diarrhea in early-onset diabetes caused by a novel R201L Kir6.2 mutation. Diabetes Care 2005;28:758-9.

18. Kumaraguru J, Flanagan SE, Greeley SA, Nuboer R, Støy J, Philipson LH, et al. Tooth discoloration in patients with neonatal diabetes after transfer onto glibenclamide: a previously unreported side effect. Diabetes Care 2009;32:1428-30.

19. Flanagan SE, Edghill EL, Gloyn AL, Ellard S, Hattersley AT. Mutations in KCNJ11, which encodes Kir6.2, are a common cause of diabetes diagnosed in the first 6 months of life, with the phenotype determined by genotype. Diabetologia 2006;49:1190-7. 